\title{
Positive Predictive Value of MRI in the Diagnosis of Intra-Abdominal Undescended Testes Taking Laparoscopic Findings as Gold Standard
}

\author{
Aasia Jehangir ${ }^{1}$, Amber Goraya $^{2}$, Abid Ali Qureshi ${ }^{3}$ \\ Post Graduate Resident, Department of Paediatric Radiology, Children Hospital \& Institute of Child Health, Lahore \\ 1 Pakistan \\ Data collection, Perform experimental work, Paper writing \\ Assistant Professor, Department of Paediatric Radiology, Children Hospital E Institute of Child Health, Lahore \\ 2 Pakistan \\ Data collection and result analysis \\ 3 Professor, Department of Paediatric Radiology, Children Hospital E Institute of Child Health, Lahore Pakistan \\ Compiled the paper \\ CORRESPONDING AUTHOR \\ Dr. Aasia Jehangir \\ Post Graduate Resident, Department of Paediatric \\ Radiology, Children Hospital \& Institute of Child \\ Health, Lahore Pakistan \\ Email: asiyajahangir01@gmail.com \\ Submitted for Publication: 10-11-2019 \\ Accepted for Publication 29-03-2021

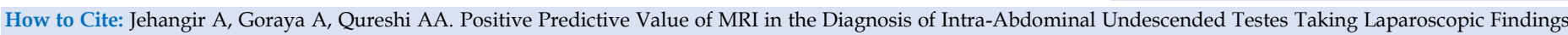 \\ as Gold Standard. APMC 2021;15(1):36-9. DOI: 10.29054/APMC/2021.762
}

\section{ABSTRACT}

Background: Cryptorchidism also known as undescended testis, is a birth defect in male babies with higher frequency in preterm infants, leading infertility and other genital problems. In its treatment, diagnosis has a vital role. Objective: The objective of this study was to determine the positive predictive value of MRI in the diagnosis of intra-abdominal undescended testes taking laparoscopic findings as gold standard. Study Design: It was a cross-sectional survey. Settings: Research was conducted at Department of Diagnostic Radiology, Children Hospital \& Institute of Child Health Lahore Pakistan. Duration: Six months from June 23, 2018 to December 22, 2018. Methodology: This study involved 68 boys aged between 2 to 15 years presenting with undescended testes. Intra-abdominal undescended testes were diagnosed on MRI and was later confirmed on laparoscopic findings which were taken as gold standard and diagnosis of MRI was judged accordingly as true positive or false positive. A written informed consent was obtained from parents of every patient. Results: The age of the children ranged from 2 years to 15 years with a mean of $8.1 \pm 3.5$ years. Majority $(\mathrm{n}=53,77.9 \%)$ of the children had right while 15 (22.1\%) children had left undescended testes. Diagnosis of intra-abdominal testes was confirmed in $64(94.1 \%)$ patients on laparoscopy. Thus, there were 64 true positive and 4 false positive cases. It yielded a positive predictive value of $94.1 \%$ for MRI in predicting intra-abdominal undescended testes taking laparoscopy as gold standard. Similar positive predictive value was noted across various age and anatomical side groups. Conclusion: The positive predictive value of MRI was found to be $94.1 \%$ in predicting intra-abdominal undescended testes taking laparoscopic findings as gold standard regardless of patient's age and anatomical side which along with its non-invasive and radiation free nature advocates its preferred use in future practice.

\section{Keywords: Undescended testes, Intra-Abdominal testes, Magnetic resonance imaging.}

\section{INTRODUCTION}

Cryptorchidism means "hidden testes" and has a usual synonym undescended testis (UDTs), is a condition when one or both testes are absent in the scrotum. ${ }^{1}$ This is most often birth defect involving male genitalia. The occurrence of undescended testes is 3\% in full term infants while $30 \%$ in preterm male infants. ${ }^{2}$ About $20 \%$ UDTs are non-palpable out of which $55 \%$ are found intraabdominally, $30 \%$ in inguinoscrotal region and 15\% are absent. Undescended testes are associated with testicular torsion, increased risk for testicular germ cell tumors, decreased fertility and psychological problems. Even without surgical intervention, UDTs have likelihood of descending till third month of life. However, if they don't descend then orchiopexy should be done at age of six months to avoid risk of infertility. 3,4

Diagnosis is the biggest problematic aspect with UDTs. If diagnosed accurately and treated appropriately, it increases the chances of proper functioning of testis in endocrine capacity i.e., fertility. ${ }^{5}$ In choosing surgical appropriate surgical approach, location of testes is helpful besides decreasing anesthesia and exploring time. For pre-operative localization of non-palpable UDTs, various imaging techniques have been used and all of them have their various limitations i.e., radiation risk, expense, contrast medium, together with the need for sedation etc. ${ }^{6,7}$

Emad-Eldin et al in an Egyptian study reported that 29 patients were suspected of intra-abdominal undescended testes on MRI, while actual intra-abdominal undescended testis was confirmed in 28 patients that produced a positive predictive value of $96.50 \%$ for MRI in the preoperative prediction of intra-abdominal undescended testis taking laparoscopy as gold standard. ${ }^{8} \mathrm{Abd} \mathrm{El}$ Gawad et al in a similar study in Egypt reported the positive predictive value of MRI to be $93.18 \%$ in predicting intra-abdominal location of an undescended testis. ${ }^{9}$ 
In the light of this evidence, MRI was a valuable tool to pre-operatively identify the intra-abdominal location of an undescended testis which may help in timely and appropriate planning of management for such patients. It also has the advantage of being non-invasive and radiation free diagnostic tool. However, the available evidence was currently limited to above mentioned two studies conducted in Egyptian population and there was no other international or local published material. As there was variation in positive predictive value with the disease prevalence, it warranted to conduct such a study in local population to further confirm the results with the hope that results of the present study may establish MRI a valuable tool for early prediction and treatment planning of such cases in future practice, thus improving the patient outcome.

\section{METHODOLOGY}

Study Design: Descriptive retrospective case series.

Settings: Radiology Department of the Children Hospital and Institute of Child Health Lahore Pakistan.

Duration: Three years and Six months from January 01, 2016 to June 30, 2019.

Sample Size: Sample size of 68 cases was calculated using $95 \%$ confidence interval and $6 \%$ margin of error taking an expected percentage of positive predictive value of MRI to be $93.18 \%$ in predicting intra-abdominal undescended testis taking laparoscopic findings as gold standard. ${ }^{9}$

Inclusion Criteria: Boys with age 2-15 years who were diagnosed intra-abdominal testis on MRI were included. Exclusion Criteria: patients with ambiguous genitalia, previous scrotal, inguinal or lower abdominal surgery and anorectal malformation and any renal malformation were excluded from the study.

Data Collection Procedure: Written informed consent to participate in the study was taken from parents of each patient. Patient's demographic details were noted. MRI was acquired with a 1.5-T MRI system (Achiva, Philips Medical Systems) using a body coil. Abdomen from the renal area above to the scrotal region below was covered. For immobilization during examination subjects with age less than five years were sedated well with chloral hydrate. The examination included axial and coronal spin-echo T1-weighted sequence (TR/TE, 450/10; flip angle, $\left.150^{\circ}\right)$, axial and coronal fat suppressed spin-echo T2-weighted sequence (5500/90; flip angle, 150). Intraabdominal location of undescended testis was labeled as per operational definition. Follow-up laparoscopy was performed and location of testis was confirmed as per operational definition considering it as gold standard and MRI results were accordingly judged as true positive or false positive as per operational definition. Patient's demographic details were noted and recorded into the attached proforma along with laparoscopic diagnosis of testicular location by the candidate herself. All the MRI Scans were performed on the same machine by the same consultant radiologist (with 5 years of teaching experience) and all laparoscopies were executed by a single laparoscopic consultant to eliminate bias. Numerical variables; age has been presented by mean \pm SD. Categorical variable i-e anatomical side (left or right) and laparoscopic diagnosis of intra-abdominal testes have been presented by frequency and percentage. Confounding variables were controlled by exclusion. Post-stratification, chi-square test has been applied taking p-value $\leq 0.05$ as significant and PPV has been recalculated. All this information was recorded into the attached proforma by the candidate.

\section{RESULTS}

The age of the children ranged from 2years to 15years with a mean of $8.1 \pm 3.5$ years. Majority $(n=53,77.9 \%)$ of the children had right while $15(22.1 \%)$ children had left undescended testes as shown in Table 1.

Table 1: Demographic characteristics

\begin{tabular}{|c|l|c|}
\hline \multicolumn{2}{|c|}{ Characteristics } & Participants (n=68) \\
\hline \multirow{4}{*}{$\begin{array}{c}\text { Age (years) } \\
8.1 \pm 3.5\end{array}$} & 2-5 Years & $17(25.0 \%)$ \\
\cline { 2 - 3 } & 5-10 Years & $33(48.5 \%)$ \\
\cline { 2 - 3 } & $\mathbf{1 0 - 1 5}$ Years & $18(26.5 \%)$ \\
\hline \multirow{2}{*}{ Anatomical Side } & Right & $53(77.9 \%)$ \\
\cline { 2 - 3 } & Left & $15(22.1 \%)$ \\
\hline
\end{tabular}

Diagnosis of intra-abdominal testes was confirmed in 64 (94.1\%) patients on laparoscopy as shown in Table 2. So, true positive were 64 while 4 cases were false. It produced a positive predictive value of $94.1 \%$ for MRI in predicting intra-abdominal undescended testes taking laparoscopy as gold standard as shown in Table 2.

Table 2: Frequency of intra-abdominal testes on laparoscopy

\begin{tabular}{|c|c|c|}
\hline Laparoscopic Diagnosis & Frequency & Percent (\%) \\
\hline Yes (True Positive) & 64 & 94.1 \\
\hline No (False Positive) & 4 & 5.9 \\
\hline Total & 68 & 100 \\
\hline
\end{tabular}

Similar positive predictive value was noted across various age and anatomical side groups as shown in Tables 3 and 4 respectively. 
Table 3: Positive predictive value of MRI across Age groups

\begin{tabular}{|c|c|c|c|c|c|}
\hline \multirow[b]{2}{*}{ Age } & \multicolumn{5}{|c|}{ Diagnosis on Laparoscopy } \\
\hline & $\begin{array}{c}\text { True } \\
\text { Positive } \\
(n=64)\end{array}$ & $\begin{array}{c}\text { False } \\
\text { Positive } \\
(n=4)\end{array}$ & Total & PPV & $\begin{array}{c}\text { P- } \\
\text { value }\end{array}$ \\
\hline $\begin{array}{c}2-5 \text { Years } \\
(n=17)\end{array}$ & $\begin{array}{c}16 \\
94.1 \%\end{array}$ & $\begin{array}{c}1 \\
5.9 \%\end{array}$ & $\begin{array}{c}17 \\
100.0 \%\end{array}$ & $94.1 \%$ & \multirow{4}{*}{0.997} \\
\hline $\begin{array}{c}\text { 5-10 years } \\
(n=33)\end{array}$ & $\begin{array}{c}31 \\
93.9 \%\end{array}$ & $\begin{array}{c}2 \\
6.1 \%\end{array}$ & $\begin{array}{c}33 \\
100.0 \%\end{array}$ & $93.9 \%$ & \\
\hline $\begin{array}{c}10-15 \text { years } \\
(\mathrm{n}=18)\end{array}$ & $\begin{array}{c}17 \\
94.4 \%\end{array}$ & $\begin{array}{c}1 \\
5.6 \%\end{array}$ & $\begin{array}{c}18 \\
100.0 \%\end{array}$ & $94.4 \%$ & \\
\hline $\begin{array}{l}\text { Total } \\
(n=68)\end{array}$ & $\begin{array}{c}64 \\
94.1 \%\end{array}$ & $\begin{array}{c}4 \\
5.9 \%\end{array}$ & $\begin{array}{c}68 \\
100.0 \%\end{array}$ & & \\
\hline
\end{tabular}

Chi-square test, observed difference was statistically insignificant, PPV: positive predictive value

Table 4: Positive predictive value of MRI across anatomical side groups

\begin{tabular}{|c|c|c|c|c|c|}
\hline \multirow{2}{*}{$\begin{array}{c}\text { Anatomical } \\
\text { Side }\end{array}$} & \multicolumn{2}{|c|}{$\begin{array}{l}\text { Diagnosis on } \\
\text { Laparoscopy }\end{array}$} & \multirow[b]{2}{*}{ Total } & \multirow[b]{2}{*}{ PPV } & \multirow[b]{2}{*}{$\begin{array}{c}\text { P- } \\
\text { value }\end{array}$} \\
\hline & $\begin{array}{c}\text { True } \\
\text { Positive } \\
(n=64)\end{array}$ & $\begin{array}{c}\text { False } \\
\text { Positive } \\
(\mathrm{n}=4)\end{array}$ & & & \\
\hline $\begin{array}{l}\text { Right } \\
(n=53)\end{array}$ & $\begin{array}{c}50 \\
(94.3 \%)\end{array}$ & $3(5.7 \%)$ & $\begin{array}{c}53 \\
(100.0 \%)\end{array}$ & $94.3 \%$ & \multirow{3}{*}{0.884} \\
\hline Left $(n=15)$ & $\begin{array}{c}14 \\
(93.3 \%) \\
\end{array}$ & $1(6.7 \%)$ & $\begin{array}{c}15 \\
(100.0 \%) \\
\end{array}$ & $93.3 \%$ & \\
\hline $\begin{array}{c}\text { Total } \\
(n=68)\end{array}$ & $\begin{array}{c}64 \\
(94.1 \%\end{array}$ & $4(5.9 \%)$ & $\begin{array}{c}68 \\
(100.0 \%)\end{array}$ & & \\
\hline
\end{tabular}

Chi-square test, observed difference was statistically insignificant, PPV: positive predictive value

\section{DISCUSSION}

In male children highly common disorder is undecided testes or cryptorchidism. ${ }^{1}$ It is not easy to examine testes physically. Therefore, if testes are not definitely identified, further evaluations should be considered to make a conclusion. Treatment need of UDTs is triggered by various associated problems like testicular torsion, testicular malignancy, increased infertility and susceptibility to trauma. Moreover, absence of one or both the testes is a physiological stigma both for the patients and their parents that leads anxiety in them. ${ }^{1-3}$ Accurate localization of testes prior to surgery is important in the management planning of such cases. ${ }^{6}$ Laparoscopy is the current gold standard but it is an invasive procedure and quest for non-invasive diagnostic tool continues. In planning surgical approach, preoperative location of the testes is helpful to reduce degree of its exploration and consequently associated time of anesthesia. For pre-operative localization, various imaging techniques have been implied. Each of them have their own limitations i.e. radiations risk, contrast medium, expense, invasiveness and all necessitating sedation. 6,7
Recent studies reported a high positive predictive value of MRI in predicting intra-abdominal location of undescended testes and advocated its preferred use owing to non-invasive and radiation free nature.., 9 However, absence of locally published material and limited presented evidence necessitated present study. The aim of this study was determination of positive predictive value of MRI in diagnosis of intra-abdominal undescended testes taking laparoscopic findings as gold standard.

Patients had mean age of the $8.1 \pm 3.5$ years in this study. Huque et al reported comparable mean age of $6.6 \pm 3.9$ years in Bangladesh ${ }^{10}$ while Inan et al reported it to be 9.0 \pm 1.4 years in Turkish such children. ${ }^{11} \mathrm{~A}$ similar mean age of $8.3 \pm 7.9$ years was observed by David et al. in boys with undescended testes in Nigeria ${ }^{12}$ while Tseng et al reported it to be $9.2 \pm 1.2$ years in Taiwan. ${ }^{13}$

We observed that majority $(77.9 \%)$ of the children had right while $15(22.1 \%)$ children had left undescended testes. A similar frequency of right $(78.9 \%)$ and left (21.1\%) undescended testes has been reported by Sheikh et al among such children presenting at The Children's Hospital and The Institute of Child Health Lahore ${ }^{14}$ while Sangrasi et al reported the frequency of right and left undescended testes to be $81.2 \%$ and $18.8 \%$ respectively at Liaquat University of Medical and Health Sciences, Jamshoro. ${ }^{15}$ Dar et al observed similar frequency of right and left undescended testes in Indian boys and reported it to be $79.0 \%$ and $21.0 \%$ respectively. ${ }^{16}$ A comparable frequency of right $(76.5 \%)$ and left $(23.5 \%)$ undescended testes has been reported by Tseng et al in Taiwan. ${ }^{13}$ Similar results have been published by Huque et al in Bangladeshi children with undescended testes; right $(78.2 \%)$ and left $(21.8 \%) .{ }^{10}$ A possible explanation for the more frequent undescended testes on right side may be the fact that during embryonic life, left testicle starts its descent first and arrives in the scrotum before the right testicle whose decent is delayed and more susceptible to arrest.

In the present study, the positive predictive value of MRI in predicting intra-abdominal undescended testes was found to be $94.1 \%$ taking laparoscopy as gold standard. Abd-El Gawad et al in a similar study in Egypt reported the positive predictive value of MRI to be $93.18 \%$ in predicting intra-abdominal location of an undescended testis. ${ }^{9}$ Similar results have also been published by EmadEldin et al in another Egyptian study who reported the positive predictive value of MRI to be $96.50 \% .{ }^{8}$ In the present study, positive predictive value of MRI was found to be $94.1 \%$ in predicting intra-abdominal undescended testes taking laparoscopic findings as gold standard regardless of patient's age and anatomical side which along with its widespread availability, noninvasive and radiation free nature advocates its preferred use in future practice. 


\section{CONCLUSION}

The positive predictive value of MRI was found to be $94.1 \%$ in predicting intra-abdominal undescended testes taking laparoscopic findings as gold standard regardless of patient's age and anatomical side which along with its non-invasive and radiation free nature advocates its preferred use in future practice.

\section{LIMITATIONS}

A very strong limitation to the present study was that we only considered cases where MRI labeled intraabdominal undescended testes while negative cases were not included which could have enabled determination of negative predictive value and diagnostic accuracy and could have established the role of MRI in the preoperative evaluation of such patients more confidently.

\section{SUGGESTIONS / RECOMMENDATIONS}

Such a study is highly recommended in future research.

\section{CONFLICT OF INTEREST / DISCLOSURE}

None.

\section{ACKNOWLEDGEMENTS}

We are thankful to our colleagues and patients who contributed in this study.

\section{REFERENCES}

1. Abacı A, Çatlı G, Anık A, Böber E. Epidemiology, classification and management of undescended testes: does medication have value in its treatment? J Clin Res Pediatr Endocrinol. 2013;5(2):65-72.

2. Niedzielski JK, Oszukowska E, Słowikowska-Hilczer J. Undescended testis - current trends and guidelines: a review of the literature. Arch Med Sci. 2016;12(3):667-77.

3. Kurz D. Current Management of Undescended Testes. Curr Treat Options Pediatr. 2016;2(1):43-51.
4. Braga LH, Lorenzo AJ. Cryptorchidism: A practical review for all community healthcare providers. Can Urol Assoc J. 2017;11(1):2632.

5. Nepal P, Kumar D, Ojili V. Abnormal descent of the testis and its complications: A multimodality imaging review. SA J Radiol. 2018;22(1):1374.

6. Pradhan MR, Ansari MS. Imaging studies for non-palpable testis: Are they at all required? Indian J Urol. 2012;28(2):227-9.

7. Hartigan S, Tasian GE. Unnecessary diagnostic imaging: a review of the literature on preoperative imaging for boys with undescended testes. Transl Androl Urol. 2014;3(4):359-64.

8. Emad-Eldin S, Abo-Elnagaa N, Hanna SA, Abdel-Satar AH.The diagnostic utility of combined diffusion-weighted imaging and conventional magnetic resonance imaging for detection and localization of non-palpable undescended testes. J Med Imaging Radiat Oncol. 2016;60(3):344-51.

9. Abd-ElGawad EA, Abdel-Gawad EA, Magdi M, Al-Minshawy SM. Magnetic resonance imaging for detection of non-palpable undescended testes: Diagnostic accuracy of diffusion-weighted MRI in comparison with laparoscopic findings. Egyptian J Radiol Nuclear Med. 2015;46(1):205-10.

10. Huque MM, Hannan MJ, Hasina K, Huq AU. Role of laparoscopy in the management of impalpable testis in children: a study in Bangladesh. Bangladesh J Endosurg. 2013;1(1):16-20.

11. Inan M, Aydiner CY, Tokuc B, Aksu B, Ayhan S, Ayvaz S, et al. Prevalence of cryptorchidism, retractile testis and orchiopexy in school children. Urol Int. 2008;80(2):166-71.

12. David OO, Iyekoretin E. Undescended testes in a developing country: a study of the management of 71 patients. Afr J Paediatr Surg. 2008;5(1):11-4.

13. Tseng CS, Chiang IN, Hong CH. Advantage of early orchiopexy for undescended testis: analysis of testicular growth percentage ratio in patients with unilateral undescended testicle. Sci Rep. 2017;7(1):174-6.

14. Sheikh A, Mirza B, Ahmad S, Ijaz L, Kayastha K, Iqbal S. Laparoscopic management of 128 undescended testes: our experience. Afr J Paediatr Surg. 2012;9(2):106-8.

15. Sangrasi AK, Laghari AA, Abbasi MR, Bhatti S. Laparoscopicassisted management of impalpable testis in patients older than 10 years. JSLS. 2010;14(2):251-5.

16. Dar SA, Bali RS, Zahoor Y, Kema AR, Bhardwaj R. Undescended testes and laparoscopy: experience from the developing world. Adv Urol. 2018;2018:1620470. 